\title{
A critical review of solid phase microextraction for analysis of water samples
}

\author{
Hamed Piri-Moghadam, Fardin Ahmadi, Janusz Pawliszyn* \\ Department of Chemistry, University of Waterloo, 200 University Avenue West, Waterloo, Ontario N2L 3G1, Canada \\ *Corresponding author: Tel. 519-888-4641, Fax. 519-746-0435, E-mail: janusz@uwaterloo.ca
}

\begin{abstract}
The review summarizes applications of solid phase microextraction (SPME) for water sample analysis. Official methods and standards of SPME in water research and inter-laboratory validation are discussed. A comparison of SPME with current EPA-approved methods from several analytical aspects is presented. The review also provides some perspectives of the recent development of SPME on sampling water using artificial river systems, in the passive sampling and on-site sampling. Recently developed configuration of SPME such as thin film microextraction and high-throughput applications (e.g. when used in a 96-blade configuration) are shown.
\end{abstract}

Keywords: Solid phase microextraction, water analysis, official and standard methods, inter-laboratory studies, on-site sampling, time weighted average 


\section{Introduction}

As the presence of environmental pollutants in ground and surface water reservoirs increasingly grows due to human activities, public concern has similarly grown over the adverse effects of environmental pollution to both the environment and human health. Serious adverse health effects such as nervous system damage, liver, kidney and eye issues, increased risk of cancer, among several other diseases [1-8] have been recognized from long-term exposure to above maximum contaminant levels (MCL) of organic pollutants such as pesticides, volatile organic compounds (VOCs), phenolic compounds, polycyclic aromatic hydrocarbons (PAHs) [1]. Considering these implications, accurate monitoring and analysis of water samples is one of the most important mandates of government environmental agencies [9]. Extraction and isolation of compounds from the sample matrices is the necessary step prior to instrumental analysis. In addition to clean-up, an ideal sample preparation technique should provide enrichment of compounds in order to improve the sensitivity. There are a number of well-established sample preparation techniques for determination of organic contaminants in water samples, including liquid-liquid extraction (LLE)[10-13], solid phase extraction (SPE),[13-15] and solid phase microextraction (SPME)[16,17]. Herein, strength and weakness of each technique is discussed from several point of view (e.g. procedure, accuracy, sensitivity, repeatability, simplicity, cost, greenness,...). LLE is a simple technique commonly used in water samples, approved by the US Environmental Protection Agency (EPA)[10]. However, in spite of routine applications of LLE, as the official method of choice of the EPA, there are some limitations associated with this technique. One of the larger criticisms of the method is directed towards its lack of 'greenness'; LLE needs large amounts of organic solvents, which in addition to being expensive and hazardous, directly affect environmental pollution. Although the method does not need any 
particular apparatus, it is nonetheless laborious and time-consuming. SPE, due to its lower need for organic solvents, is an sample preparation technique poised to replace LLE [14]. However, SPE has its own shortcomings, generally related to carry-over associated with automation and sample pre-treatment. As well, suspended solids and particulate are required to be filtered prior to the SPE procedure, which can result in loss of compounds, particularly hydrophobic ones, which in turn influences the overall accuracy of the method. As an alternative to these traditional methods, SPME has been introduced by Pawliszyn [16] in the early 1990s as a solvent-free, economical, simple, and rapid method. In SPME, the extraction phase, placed on a solid support, is exposed to the sample for extraction of compounds, and then followed by coupling to an appropriate analytical instruments for desorption and determination, including gas chromatography (GC)[17-19], liquid chromatography (LC)[18-22] and direct coupling to mass spectrometry (MS)[23-29]. Since its introduction, different geometries of SPME including fiber, miniaturized SPME, in-tube (capillary microextraction), in-tip, stir bar, vessel walls, disk/membrane, magnetic nanopatricles and thin film microextraction (TFME) $[17,29,30]$ have gained broad acceptance for analysis of target compounds in several matrices (i.e. water samples[17], biofluids[31], tissue[32]). SPME frequently overcome the aforementioned limitations associated with traditional sample preparation techniques due to no or minimum solvent consumption, while providing several other advantages, including a wide range of applications owing to several types of coatings and geometries[17,33], capability of correct quantitation of sediment pore water[34], selectivity[33] as well as easy automation to GC[17] and LC[22,35] instruments, which may not be easily achieved by traditional sample preparation techniques. Benefiting from negligible depletion[17,36] of extraction due to the small size of its extraction phase, SPME can determine free and total amounts of target compounds without 
disturbing the system, unlike exhaustive extractions provided by LLE and SPE [37,38]. Several well-documented reviews of SPME have been published for a variety of applications $[17,21,31,33,35,39-43]$.

In spite of all the aforementioned advantages of SPME, it has not been adopted in contract analytical laboratory yet, and many laboratories are still using LLE and SPE as official US EPA method for routine analysis of organic contaminations in water sample. The purpose of this review is to show that the SPME method might be adopted as a standard protocol by a commercial analytical testing laboratory. To do so, SPME method was compared with official sample preparation techniques to evaluate strength and shortcoming of SPME. The broad application of SPME for water sample analysis, standard methods and inter-laboratory validation were also shown. It has been discussed that SPME not only has similar accuracy and repeatability to official methods but it also provides more perspectives and capabilites for analysis of water samples. Thus, new development and perspective of SPME in water sample analysis is discussed as advantages of SPME technique over conventional methods (e.g. on-site, passive and TWA sampling).

\section{2- SPME in water sample analysis}

Provided the multiple advantages of SPME such as simplicity, greenness, speed as well as integration of sampling, extraction, and pre-concentration in one step, it has been in the center of attention for analysis of water samples. It should be emphasized that analysis of water samples 
for determination of acid/base/neutral compounds (ABNs) by LLE is cumbersome, as each group is needed to be separately extracted by adjusting the $\mathrm{pH}$. On the other hand, simultaneous determination of large numbers of pesticide ABNs from different classes has been demonstrated by SPME. Validation of the SPME method for simultaneous determination of 46 pesticides with a wide range of polarities and chemical structures (organochlorine, organophosphorous, triazines, pyrethroids and others) in water samples by GC-MS was reported by BeceiroGonzalez et al.[44] by application of $100 \mu \mathrm{m}$ PDMS, $85 \mu \mathrm{m}$ PA, and $60 \mu \mathrm{m}$ PDMS/DVB. In addition to simultaneous determination of ABNs, low limit of detection (LOD) values ranging from 4-17 ng mL ${ }^{-1}$ were reported, which is of great importance for trace analysis of compounds. Some well-established studies regarding simultaneous determinations of ABNs in water samples with sub-PPb limits of quantification by Rodriguez-Lafuente et al. [45](determination of 25 compounds) and Goncalves et al.[46,47] (44 and 34 compounds) are also available. In addition to obtaining low/no carryover amounts, good accuracy and repeatability were obtained by SPME.

Application of HPLC is the general method of choice for determination of polar, less volatile, and thermally labile compounds. Coupling of SPME to LC via a designed interface was first reported in 1995 by Chen et al.[48] for analysis of PAHs in water samples. A design providing fiber vibration was also developed for determination of selected triazines in water samples[49]. On-line extraction/desorption was accomplished by coupling in-tube SPME to LC for determination of non-volatile compounds such as carbamates[50].

Table 1 shows a summary of applications of SPME for quantitation of a wide range of organic pollutants in different water samples. 


\section{3- Official methods and standards of SPME for analysis of water samples}

The prevalence of SPME for analysis of water samples has been significantly increasing due to the method's automation to GC instruments. Acceptance of SPME as the official method and standard by US-EPA, ISO and ASTM organizations shows that this technique could be employed as a regulatory method in routine analyses. Although there are several official methods of SPME for different samples and applications, only the standards related to water samples are presented.

\subsection{US EPA Method 8272, 2007 (PAHs in sediment water)}

So far, there is one test method based on SPME approved by the US EPA, which is method 8272 for the determination of PAHs in sediment pore water followed by GC-MS [34]. There are several advantages of SPME for sediment pore water analysis that outweigh regulatory methods based on solvent extraction. Large amounts of water samples, in the liter range, as well as large consumption of organic solvents are needed when conventional solvent extraction techniques are used. In addition, filtration is also required in traditional methods to produce pore water. Filtration and solvent evaporation/reconstitution result in loss of PAHs of low molecular weight. The approved US-EPA SPME method has been employed for determinations of PAHs in pore water in a wide concentration range, between nanograms to milligrams per litre, something which is not achievable with the use of official solvent extraction methods. Using SPME methodology, a small volume of pore water, $1.5 \mathrm{~mL}$, is sufficient for extraction, with no generation of organic solvent waste. Notably, LOQs ranging from $0.06 \mu \mathrm{g} \mathrm{L}^{-1}$ for high molecular 
weight PAHs (i.e. benz(a)anthracene and chrysene), to $9 \mu \mathrm{g} \mathrm{L}^{-1}$ for low molecular weight PAHs was achieved by this method.

\subsection{International Standardisation Organisation (ISO) 27108, 2013 (Pesticides in water)}

This method includes determination of plant treatment agents and biocide products in drinking, ground and surface water samples by SPME-GC-MS[102]. Limits of detection are related to the matrix, but can be achieved to at least $0.05 \mu \mathrm{g} \mathrm{L}{ }^{-1}$. Validation of results in the range of $0.05-0.3$ $\mu \mathrm{g} \mathrm{L}^{-1}$ has been demonstrated in an inter-laboratory trial.

\subsection{ISO 17943 (VOCs in water)}

Recently, worldwide inter-laboratory experiments were accomplished for analysis of water to determine VOCs by HS-SPME [103]. These results could release a new ISO 17943, which is currently under development. These experiments are related to the determination of 63 VOCs in different water matrices including drinking, surface, ground, and waste water samples by HSSPME-GC-MS. In this trial, a DVB-CAR-PDMS fiber was used to develop a reliable and reproducible method. Recovery rates ranging from $84-116 \%$ for surface water and $81-118 \%$ for waste water samples were achieved.

\subsection{American society for testing and materials (ASTM) D 6520, 2000:}

In ASTM D6520, procedure involving extraction of semi-VOCs and VOCs by SPME is presented. It is a standard practice to apply SPME both directly to water as well as its headspace followed by GC and GC/MS determination. [104]. In this standard, principle of SPME, interferences, selection of fiber phase and SPME apparatus (i.e. SPME holder, SPME fiber assembly and SPME injector liner) is shown. Moreover, optimization of SPME parameters (e.g. 
temperature, ratio of liquid to headspace, vial size, acidity of sample, ...), calibration, standardization and analysis are demonstrated. It should be noted that a wide range of compounds including VOCs, organochlorine and organophosphorous pesticides, PAHs, PCBs, phenols, nitrophenols and amines can be determined by this standard procedure [104].

\subsection{ASTM D 6889, 2003:}

It is standard practice to apply SPME for fast screening of volatile organic compounds in water [105]. The standard is related to trace analysis of VOCs in water samples by fast GC-FID. Table 2 shows official methods and standards of SPME for water analyses.

\section{4- Inter laboratory studies of SPME}

The number of successful applications for quantitative analyses in water samples by SPME has been rapidly increasing; some of these applications can be found in Table 1 . However, interlaboratory studies are the pivotal key for worldwide acceptance of SPME by standardization organizations. In this regard, several inter-laboratory studies have been accomplished to demonstrate the applicability of SPME for water analyses. For instance, Gorecki et al.[106] conducted inter-laboratory studies for determination of semi-VOCs in water samples by SPME. The analysis was performed at low $\mathrm{ng} \mathrm{mL}^{-1}$ of 12 pesticides from organochlorine, organonitrogen, and organophosphate groups by PDMS fiber followed by GC/MS. Eleven European and North American laboratories[106] (Poland, Italy, Germany, Belgium, Canada, and USA) participated in the study, following the same procedure for analysis of aqueous water spiked with target compounds at 1 and $10 \mathrm{ng} \mathrm{mL} \mathrm{m}^{-1}$, obtaining calibration curves, and performing 
blind analyses. Excellent linearity of the calibration curve was obtained while results confirmed the satisfactory repeatability, reproducibility, and accuracy of the SPME technique.

Nilsson et al.[107] also conducted an inter-laboratory demonstration for validation of SPME for quantitation of VOCs in water samples. Twenty laboratories were involved in the study and two approaches were applied, HS-SPME and direct-SPME, with PDMS fibers as extraction phase coupled to GC-MS, GC-FID and GC-ECD instruments. In all cases, LOD values in low ppt levels, good linearity, and precision were achieved. ISO standard 5725, based on analysis of variance (ANOVA), was applied to statistical data treatment for evaluation of accuracy and precision of the SPME method. Comparison of SPME with reference methods, including purge and trap (P\&T) and static headspace (HS) techniques, was conducted [107]. The obtained results demonstrated the comparable accuracy of SPME with the reference methods P\&T and HS[107].

Inter-laboratory validation of SPME for determination of triazine herbicides and their degradation products at the ppt level was also reported[108]. Ten laboratories participated to conduct the experiment, and validation of the SPME method was performed by CW-DVB fiber, followed by GC/MS and GC-NPD. An LOD of $50 \mathrm{ng} \mathrm{mL}^{-1}$ with good linearity was achieved. Satisfactory repeatability (RSD of 6-14 \%) and reproducibility (RSD of 10-15 \%) were obtained. It is important to emphasize that good accuracy was attained in all laboratories, confirming the applicability of SPME for determination of pesticides in water samples as an alternative technique to conventional methods.

Recently, performance of HS-SPME was validated [103] for determination of VOCs in water samples, a procedure which is under development as the new ISO 17943. This study was 
composed of 42 participant laboratories from 16 countries (Austria, Brazil, Canada, Croatia, France, Germany, Great Britain, Italy, Portugal, Romania, Serbia, South Africa, Spain, Sweden, Switzerland and United States). More than 60 compounds were included in this study, including halogenated hydrocarbons, trihalogen methans, and gasoline additives (BTEX, MTBE and ETBE), for analysis of drinking, ground, and surface water by DVB-CAR-PDMS fiber. Good repeatability was obtained for most of the compounds (RSD less than $10 \%$ in surface water and RSD $8 \%$ in waste water). Reproducibility less than $31 \%$ in surface water and less than $35 \%$ for waste water were also reported. In addition, recovery rates (from assigned value) ranged from 84-116 \% (surface water) and 81-118 \% (waste water) for most of the target analytes.

\section{5- Comparison of SPME and EPA-approved methods}

\subsection{SPME and LLE}

There are a number of publications regarding comparisons of SPME with LLE[88,109-112] (Table 3). Recently, Rodriguez-Lafuente et al. [45] validated automated SPME method through a comparison with the LLE method based on US EPA methods 3510C and 8270D with some modification, by split blind analyses of spiked surface and ground water samples with 25 pesticides from different classes. Multi fiber exchange (MFX) autosampler was used for automation selection of SPME fiber. Reported detection limits (RDL) were in the range of 0.5-5 ng $\mathrm{mL}^{-1}$ by LLE technique, while SPME fibers achieved RDL values ten times lower, ranging from 0.05 to $0.5 \mathrm{ng} \mathrm{mL}^{-1}$. A comparison of results obtained by LLE and SPME with the use of a Blond-Altman plot for approximately 400 points showed good agreement between the two techniques. Both techniques were shown to be accurate, with highest accuracy results in the 
range of $70-130 \%$. An eco-scale assessment of greenness was also used to assess both methods ${ }^{[42,110]}$; the scale is based on penalty points that are assigned according to usage of chemicals, consumption of energy, and waste generation. An eco-scale factor of 82 was obtained by the SPME method (18 penalty points), in comparison to an eco-scale factor of 51 for LLE, affirming the superior greenness of the SPME technique. Apart from good accuracy, SPME benefits from low sample requirements, ranging from 2-10 mL, as compared to LLE, for which up to $1 \mathrm{~L}$ of sample is needed. On the other hand, LLE provides simplicity with no requirement to any particular apparatus and easy quantitation due to exhaustive extraction.

SPME method for analysis of haloacetonitriles (HANs), haloketones (HKs) and chloropicrin (CP) in drinking water was validated by Riazi Kermani et al. [112] by comparison with LLE technique, EPA method 551.1. Fast automated HS-SPME-GC-MS, 30s min including extraction and chromatographic run, with good sensitivity at ng $\mathrm{L}^{-1}$ levels was achieved by DVB/CAR/PDMS fiber for determination of the selected compounds in drinking water. Comparison of the results of sample analysis by the HS-SPME-GC-MS and the LLE-GC-ECD methods revealed good agreement of SPME and LLE methods indicating applicability of the developed SPME method for rapid analysis of these disinfection by-products in drinking water samples. Riazi Kermani et al. [112] also compared HS-SPME-GC-MS for the analysis of trihalomethanes (THMs) in source and drinking water samples with LLE-GC-ECD method derived from EPA 551.1. Study was peformed by analysis of thirty water samples received from six water treatment plants and distribution systems in Canada by both methods. Statistical methods were applied to the obtained results which proved good agreement and equivalency between SPME and LLE. 
One limitation of SPME method is related to error associated with analysis of hydrophobic compounds as they stick to the wall of the bottle/container which sampling is performed. On-site sampling by SPME is one of the on-going methods which not only can address this issue in order to accurately quantify the sticky compounds but also it is in a great importance when immediate decision is required upon the results obtained on-site (on-site sampling is further discussed in section 6).

\subsection{SPME and SPE}

There are well-documented publications regarding comparisons of SPME and SPE [114-118]. For instance, Sakamoto et al.[114] reported determination of 38 pesticides in water samples by SPME and SPE (Table 3). The obtained results showed a good degree of agreement between the two techniques, with RSD\% $\leq 12.5$. For SPME, only $10 \mathrm{~mL}$ of sample was used, while $500 \mathrm{~mL}$ had to be loaded to the SPE cartridge. For SPE, before loading of each sample, SPE cartridges have to be conditioned by different solvents, and vaporization of solvents is often required in order to obtain an acceptable concentration of compounds for analysis. Conversely, no/minimum conditioning is needed for SPME fiber, and desorption can often be directly performed in GC injectors. A cost analysis of SPME and SPE has also 
been performed by Dalvie et al.[119], as the final goal was implementation of a technique for monitoring of pesticides in water samples in South Africa. Annual capital costs, including building and equipment, and recurrent costs, including transport, personnel, supplies, and building operating costs were estimated and added to evaluate the cost of analysis per sample. The obtained estimation revealed that SPME has a lower cost (US \$ 37 analysis per sample) compared to SPE (US \$ 48.5 analysis per sample). Provided the lower cost of SPME as well as its superior sensitivity, reliability, and faster output, this technique can be said to be an ideal method for long-term monitoring of pesticide pollution in water samples. It is worth noting that in the aforementioned study, cost of ELISA was US \$ 60 for analysis per sample. Easy automation of SPME fiber to GC/MS makes this technique suitable for analysis of water sample while lower amount of sample is required. On the other hand, SPE provides higher sensitivity and easy calibration due to exhaustive extraction. However, a limitation of both techniques is the nature of hydrophobic analytes to stick to the walls of sampling containers/bottles, limiting the accuracy of the determination. On-site sampling by 
SPME is a promising approach as the future trends to overcome the aforementioned issue.

\subsection{SPME and P\&T}

P\&T is a well-known technique for analysis of volatile organic compounds in water samples[9]. Comparisons of SPME and P\&T techniques and inter-laboratory validation have been conducted [107,120-122]. MacGillivray et al. [123] compared SPME with the P\&T technique for analysis of BTEX in water samples. A plot of SPME versus P\&T showed good agreement between two techniques with comparable statistical method detection limits. However, while SPME is a simple and relatively inexpensive technique, P\&T equipment is expensive and suffers from the risk of leaking [123]. In addition, P\&T often incurs sample carryover, and is burdened with problems associated with water management. Table 3 shows a comparison of SPME with LLE, SPE, and P\&T methods.

\section{6- New developments and perspectives of SPME for water analysis}

\subsection{Thin film microextraction (TFME)}

The sensitivity of the SPME technique can be enhanced by increasing the volume of the extraction phase. However, thicker coatings lead to longer extraction times, which may not be favourable. TFME was developed to enhance sensitivity without sacrificing extraction time; this is accomplished due to the increased surface area-to-volume ratio of the membrane $[43,125]$. This geometry offers higher sensitivity in comparison to traditional SPME fibers, which is beneficial for analysis of water samples for determination of compounds present at trace levels. Provided with a higher extraction rate, larger amounts of analyte can be extracted in shorter 
extraction time by TFME compared to SPME fibers. A comprehensive study of the PDMS membrane for determination of selected PAHs in lake water was reported by Bruheim et al.[125], where PDMS membranes and fibers were compared in regards to both direct and headspace (HS) extraction modes. Further development of new membranes was also demonstrated, including impregnation of CAR/PDMS and PDMS/DVB TFME on glass wool fabric to improve extraction efficiencies for analysis of N-nitrosamines (NAs) in water samples (Fig. 1a) [126]. After extraction, desorption and analysis was performed using thermal desorption unit (TDU) and GC/MS instrument. Comparison of membrane and fiber, with the same coating, showed that TFME had about 110 times higher extraction efficiency for the short sampling time which is close the ratio of surface area of membrane and fiber while the corresponding ratio for longer extraction time was close to 40, close to the volume ratio for extraction of N-nitrosodimethylamine, N-nitrosomethylethylamine, N-nitrosodiethylamine and N-nitrosopiperidine from water samples. Direct coupling of TFME and desorption electrospray (DESI)/MS was reported by Strittmatter et al [127] for analysis of wastewater samples. Porous mixed mode C18/SCX sorbent with $25 \mathrm{~mm}$ coating thickness was employed as coating of TFME. The main goal of direct coupling of TFME/DESI was to introduce an alternative method to TFME followed by elution and LC-MS/MS to have short analysis time

Kumar et al. has proposed another version of impregnated fabric based TFME, fabric phase sorptive extraction (FPSE) [128] by coating sol-gel materials on the fabric to benefit from porous cellulose surface, which was used as substrate, all the properties of sol-gel materials including thermal stability, wide range of coating chemistry and selectivity. Application of FPSE for determination of benzotriazole in sewage samples [129], non-steroidal anti-inflammatory drugs 
from environmental water samples [130], analysis of alkyl phenols in environmental samples [131], and determination of emerging contaminants from environmental water samples [132] were reported. Preparation of robust membrane was reported by coating PDMS/DVB on the carbon mesh support to facilitate extraction at high agitation rate and on-site sampling. It was used to push down the limit of detection of some selected pesticides in water sample by benchtop and portable GC/MS instruments [133].

Another format of TFME was reported by Cudjoe et al.[134] which called 96-blade configuration and allows high-throughput analysis. As Fig. 1b,c shows high throughput analysis was achieved by the 96blade operated by a robotic autosampler. This configuration was employed for determination of phenolic compounds in water sample using carboxylated multiwall carbon nanotube coupled to HPLC[135]. High extraction efficiency in the range of $60-90 \%$ recovery with $\mathrm{RSD}$ $\leq 6 \%$ was presented for the selected chlorophenols. High-throughput analysis was achieved, 2.1 min for each sample, due to capability of analysis of 96 samples per $200 \mathrm{~min}$. In addition, 96-blade SPME format offered several advantages including ease of use, fast procedure, relative low cost, easy automation, and need for small amount of sample (1.2 mL per sample). Application of high throughput TFME for determination of quaternary ammonium compounds in water samples 
using LC/MS/MS was also reported[136]. Similarly, fast (less than 1 min per sample) analysis was obtained by 96 high-throughput TFME. Applicability of the high-throughput 96-blade configuration was proved for analysis of a large number of quaternary surfactants possessing a wide of physicochemical properties while an acceptable $\mathrm{LOQ}$ in the range of 0.01 to $0.25 \mathrm{ng} / \mathrm{mL}$ with wide linear dynamic range were obtained.

Detection of pharmaceutical residues in wastewater samples by TFME, automataed 96-blade high-throughput configuration, coupled to LC/MS was reported by Togunde et al.[137]. Exhaustive extraction was achieved for the selected compounds by C18 blade compared to C18 fiber due to lager surface area-to-volume ratio and higher capacity of the blade. This technique is called open bed SPME and no vacuum pump is needed to pass the sample through the bed. The open bed SPME was validated by comparison with SPE technique for analysis of wastewater effluent samples, and the results proved good agreement between two techniques. It should be noted that no pre-treatment was required for open bed SPME while particles/matrix-rich samples can potentially clog the SPE cartridge as a packed bed system. Filtering the sample for removal of particles can result in loss of matrix-bound analytes which subsequently affects accuracy of the method. Therefore, open bed SPME compare to SPE has advantages of lower cost, simplicity, fast extraction procedure and no requirement for sample pre-treatment or vacuum pump. Theoretically and experimentally comparison of TFME and SPE methods, considered as microextraction versus exhaustive extraction, was reported by Mirnaghi et al.[138] by extraction 
of doping substances in wide range of polarity at low and high volumes of sample. The results showed that extraction recoveries of TFME and SPE for $1 \mathrm{~mL}$ of sample were comparable for all of the compounds except the most polar ones. Moreover, one issue of SPE technique is related to breakthrough volume at higher sample volumes. In such a case, exhaustive principle of quantitation cannot be used to get reliable and accurate results. This can be a critical challenge for SPE when dealing with untargeted determination where there is no information available about breakthrough volume while it does not affect SPME due to equilibrium based calibration methods. There is a well documented review regarding comparison of SPME and exhaustive extraction approaches[38].

\subsection{On-site sampling}

There are always errors associated with transportation of samples from site to laboratory. Loss of analytes on the sampling container particularly for hydrophobic compounds and decomposition, are two most common source of error, which is particularly important for approaches which take sub-samples from the collection vessels. On-site sampling based on SPME produces accurate, precise, and fast analytical data, while reducing the overall possibility of errors by eliminating the aforementioned sources of errors. Analytes have been demonstrated to be more stable in the coating rather than in the sample matrix [139]. In addition on site sampling particularly combined with on-site determination make the water monitoring "greener" as it eliminates necessity of transporting water samples to the laboratory. SPME has been widely used for on-site sampling of PAHs compounds in aquatic environments [140-147]. The technique can be 
performed either by spot or passive sampling for short- and long-term monitoring, respectively. In spot sampling, the SPME fiber or thin film is assembled on the electric drill and applied for rapid sampling (Fig. 1a,b)[141,148]. The sampling rate is controlled by the agitation speed of the drill, since it is easy to keep drill rotation at a stable speed. In short exposure times, concentrations and sampling rates should be sufficiently high to reach high sensitivity for quantitative analysis. A high sampling rate can be achieved by using TFME membranes, as they provide more sensitivity due to the larger surface-area-to-volume ratio [141]. On the other hand, in passive sampling, analytes move from the sampling medium to the extraction phase because of the difference in chemical potential between the matrix and extraction phase [149-151]. Calibration is a critical step in the on-site sampling process to obtain accurate and reliable quantitative data. In SPME, extraction of compounds from sample matrix to extraction phase occurs through diffusion in the boundary layer [43]. Based on this principle, several types of calibration techniques have been developed. These calibration methods include sampling rate calibration [141,152], equilibrium based calibration [153], in fiber standardization [154-156], predominant desorption kinetic calibration [157], standard free kinetic calibration [140], onecalibrant kinetic calibration [146], and diffusion based calibration [142]. Passive sampling can also be used for obtaining time weighted average (TWA) concentrations of analytes. TWA sampling provides a realistic picture of aquatic-life continuous exposure to organic contamination for prolonged periods of time. [158,159] Retracted devices and open bed configurations are two most commonly used formats of SPME for TWA sampling (Fig. 3) ${ }^{[139-}$ ${ }^{141]}$. In the retracted device, the fiber or thin film blade is retracted to a known distance in the needle housing or copper tube. The mass transfer is controlled by diffusion of analytes in stagnant water layer in the diffusion barrier between the opening of the device and the coating. 
However, there are some limitations associated with this sampler, such as loss of hydrophobic compounds in the diffusion path [160], low fiber capacity and low sampling rate. [142] In addition, the applied PDMS is not an adequate coating for extraction of hydrophilic and volatile compounds due to its low affinity and unsuitability as a zero sink[161]. Recently, Ahmadi et al. developed a TF-SPME retracted device incorporated to a hydrophilic-lipophilic balance (HLB) sorbent for TWA sampling of hydrophilic UV filter compounds in water [162]. In addition, open bed configuration was introduced to remove/minimize loss of hydrophobic analytes in the diffusion path in the retracted device configuration (Fig. 3). In this configuration, the SPME device is exposed directly to the sampling media, and kinetic calibration is used to obtain TWA concentrations when the extraction process is in the linear uptake regime [143,144]. In this strategy a sampler was placed in a copper bag in order to prevent biofouling during the sampling process (Fig. 3d,e).

\subsection{Flow-through standard water generator (artificial river system)}

Preparation of steady state concentrations of highly hydrophobic compounds in water is challenging. Partial precipitation, losses on the sampling container, low solubility in water, and limited sample volumes are some of the problems associated with in-vial preparation of aqueous standards of hydrophobic compounds for evaluation of passive sampler devices. As such, finding a reliable and reproducible alternative approach for preparation of standard aqueous solution is highly necessary. To date, different types of flow-through standard aqueous generators have been developed.[163,164] Direct infusion of standard solutions dissolved in organic solvent by syringe pump was first used to obtain partition coefficients of PAHs compounds between water and the PDMS coating. [163] The syringe pump is an electrical/mechanical device that is 
susceptible to failure and it is inconvenient to use due to the need for periodic refilling for long term monitoring of target analytes in water. Another disadvantage of the pump system is the need for addition of organic solvents to standard solutions with the tested chemicals, which can affect SPME recovery [165]. To address these shortcomings, Ouyang et al. developed an alternative system based on permeation of solid hydrophobic compounds through the dialysis membrane for evaluation of different types of TWA samplers [164]. The system is consisted of a permeation chamber, mixing chamber, sampling chamber, and sampling cylinder, and was used for development of an SPME TWA sampler for PAHs compounds in water. A modified flowthrough standard aqueous generator system was recently developed [166] to extend the capability of the current system to include a wide variety of chemical compounds, from liquid hydrophobic to solid hydrophilic compounds (Fig. 4). A dialysis membrane, permeation tube, and porous frit coated with epoxy glue were used to produce a steady state concentration of UV filters and biocides in water [166]. The current system was used for development and evaluation of a thin film SPME passive sampler, and investigation of partitioning of UV filters and biocides to different environmental compartments such as humic acid and sediment.

\section{Conclusion}

Application of SPME for determination of organic pollutants in water samples is increasing due to several advantages of SPME over conventional extraction techniques. Inter-laboratory studies and comparisons with EPA-approved methods have been performed to evaluate the accuracy and applicability of SPME for routine analysis of water samples, subsequently resulting in publications of ISO and standard method. Future trends of SPME for on-site sampling include 
improvements in the accuracy of determination for hydrophobic and unstable compounds, which may be potentially lost during transportation from site locations to laboratories. More recent investigations directed towards monitoring water quality via on-site determination of contaminants accumulation level in fish tissue and other biota has demonstrated to be very useful as it takes advantage of non-lethal feature of SPME approach [167]. Direct coupling of SPME to MS is also another promising approach toward rapid and sensitive analysis of water samples [24, 25, 27-29]. Generally it can be said that while accuracy of SPME method is in a good agreement with official methods, it can overcome some concern regarding the greenness of LLE technique and provides broader range of applications.

\section{Acknowledgment}

The authors thank the Natural Sciences and Engineering Research Council of Canada (NSERC) for their financial support. 


\section{References}

[1] U.S. Environmental Protection Agency (EPA), Washington, DC. "List of Contaminants and their MCLs.,".

[2] M.C.R. Alavanja, J. a Hoppin, F. Kamel, Health effects of chronic pesticide exposure: cancer and neurotoxicity., Annu. Rev. Public Health. 25 (2004) 155-197.

[3] M.C.P. Espada, A. G. Frenich, J.L.M. Vidal, P. Parrilla, Comparative Study Using Ecd, NPD, and MS/Ms Chromatographic Techniques in the Determination of Pesticides in Wetland Waters, Anal. Lett. 34 (2001) 597-614.

[4] R. Yu, Q. Liu, J. Liu, Q. Wang, Y. Wang, Concentrations of organophosphorus pesticides in fresh vegetables and related human health risk assessment in Changchun, Northeast China, Food Control. 60 (2016) 353-360.

[5] M.F. Bouchard, J. Chevrier, K.G. Harley, K. Kogut, M. Vedar, N. Calderon, et al., Prenatal exposure to organophosphate pesticides and IQ in 7-year-old children, Environ. Health Perspect. 119 (2011) 1189-1195.

[6] A.J. Handal, B. Lozoff, J. Breilh, S.D. Harlow, Effect of community of residence on neurobehavioral development in infants and young children in a flower-growing region of Ecuador, Environ. Health Perspect. 115 (2007) 128-133.

[7] H.G. Gorchev, G. Ozolins, WHO guidelines for drinking-water quality., WHO Chron. 38 (1984) 104-108.

[8] J. Jurewicz, W. Hanke, Prenatal and childhood exposure to pesticides and neurobehavioral development: review of epidemiological studies., Int. J. Occup. Med. Environ. Health. 21 (2008) 121-132.

[9] C.J. Koester, R.E. Clement, C.J. Koester, R.E. Clement, Critical Reviews in Analytical Chemistry Analysis of Drinking Water for Trace Organics Analysis of Drinking Water for Trace Organics, 2015.

[10] D. Barcelo, Environmental Protection Agency and other methods for the determination of priority pesticides and their transformation products in water, J. Chromatogr. 643 (1993) 117-1436.

[11] B.M. Mahara, J. Borossay, K. Torkos, Liquid - Liquid Extraction for Sample Preparation prior to Gas Chromatography and Gas Chromatography - Mass Spectrometry Determination of Herbicide and Pesticide Compounds, 58 (1998) 31-38.

[12] I.H. Suffet, S.D. Faust, The p-value approach to quantitative liquid-liquid extraction of pesticides from water. 1. Organophosphates: choice of pH and solvent., J. Agric. Food Chem. 20 (1973) 5256.

[13] M.C. Hennion, V. Pichon, D. Barceĺ, Surface water analysis (trace-organic contaminants) and EC regulations, TrAC - Trends Anal. Chem. 13 (1994) 361-372.

[14] C. Erger, T.C. Schmidt, Disk-based solid-phase extraction analysis of organic substances in water, TrAC Trends Anal. Chem. 61 (2014) 74-82.

[15] T. Pihlström, A. Hellström, V. Axelsson, Gas chromatographic analysis of pesticides in water with off-line solid phase extraction, Anal. Chim. Acta. 356 (1997) 155-163.

[16] C. Arthur, J. Pawlyszin, Solid phase microextraction with thermal desorption using fused silica optical fibers, Anal. Chem. 62 (1990) 2145-2148. 
[17] É.A. Souza-Silva, R. Jiang, A. Rodríguez-Lafuente, E. Gionfriddo, J. Pawliszyn, A critical review of the state of the art of solid-phase microextraction of complex matrices I. Environmental analysis, TrAC Trends Anal. Chem. 71 (2015) 224-235.

[18] D. Vuckovic, S. Risticevic, J. Pawliszyn, In vivo solid-phase microextraction in metabolomics: Opportunities for the direct investigation of biological systems, Angew. Chemie - Int. Ed. 50 (2011) 5618-5628.

[19] S. Risticevic, H. Lord, T. Górecki, C.L. Arthur, J. Pawliszyn, Protocol for solid-phase microextraction method development., Nat. Protoc. 5 (2010) 122-39.

[20] B. Bojko, J. Pawliszyn, In vivo and ex vivo SPME: a low invasive sampling and sample preparation tool in clinical bioanalysis., Bioanalysis. 6 (2014) 1227-39.

[21] É.A. Souza-Silva, N. Reyes-Garcés, G.A. Gómez-Ríos, E. Boyaci, B. Bojko, J. Pawliszyn, A critical review of the state of the art of solid-phase microextraction of complex matrices iii. bioanalytical and clinical applications, TrAC Trends Anal. Chem. 71 (2015) 249-264.

[22] H.L. Lord, Strategies for interfacing solid-phase microextraction with liquid chromatography, J. Chromatogr. A. 1152 (2007) 2-13.

[23] M. Walles, Y. Gu, C. Dartiguenave, F.M. Musteata, K. Waldron, D. Lubda, et al., Approaches for coupling solid-phase microextraction to nanospray, J. Chromatogr. A. 1067 (2005) 197-205.

[24] G.A. Gómez-Ríos, J. Pawliszyn, Development of Coated Blade Spray Ionization Mass Spectrometry for the Quantitation of Target Analytes Present in Complex Matrices, Angew. Chemie. 53 (2014) 14731-14735.

[25] G.A. Gómez-Ríos, J. Pawliszyn, Solid phase microextraction (SPME)-transmission mode (TM) pushes down detection limits in direct analysis in real time (DART), Chem. Commun. 50 (2014) 12937-12940.

[26] Y. Zhao, X. Gong, X. Si, Z. Wei, C. Yang, S. Zhang, et al., Coupling a solid phase microextraction (SPME) probe with ambient MS for rapid enrichment and detection of phosphopeptides in biological samples, Analyst. 140 (2015) 2599-2602.

[27] S. Ahmad, M. Tucker, N. Spooner, D. Murnane, U. Gerhard, H. Sg, Direct Ionization of SolidPhase Microextraction Fibers for Quantitative Drug Bioanalysis: From Peripheral Circulation to Mass Spectrometry Detection, Anal. Chem. 87 (2015) 754-759.

[28] J. Deng, Y. Yang, L. Fang, L. Lin, H. Zhou, T. Luan, Coupling Solid-Phase Microextraction with Ambient Mass Spectrometry Using Surface Coated Wooden-Tip Probe for Rapid Analysis of Ultra Trace Perfluorinated Compounds in Complex Samples, Anal. Chem. 86 (2014) 1115911166.

[29] H. Piri-moghadam, F. Ahmadi, G.A. Gómez-ríos, E. Boyaci, N. Reyes-Garcés, A. Aghakhani, et al., Fast Quantitation of Target Analytes in Small Volumes of Complex Samples by MatrixCompatible Solid-Phase Microextraction Devices Communications Angewandte, Angew. Chemie. (2016). doi:10.1002/anie.201601476.

[30] H. Lord, J. Pawliszyn, Evolution of solid-phase microextraction technology, J. Chromatogr. A. 885 (2000) 153-193.

[31] G. Ouyang, D. Vuckovic, J. Pawliszyn, Nondestructive sampling of living systems using in vivo solid-phase microextraction., Chem. Rev. 111 (2011) 2784-814. 
[32] E. Cudjoe, B. Bojko, I. de Lannoy, V. Saldivia, J. Pawliszyn, Solid-Phase Microextraction: A Complementary In Vivo Sampling Method to Microdialysis, Angew. Chemie Int. Ed. 52 (2013) 12124-12126.

[33] E.A. Souza Silva, S. Risticevic, J. Pawliszyn, Recent trends in SPME concerning sorbent materials, configurations and in vivo applications, TrAC - Trends Anal. Chem. 43 (2013) 24-36.

[34] USEPA (U.S. Environmental Protection Agency), Method 8272, 2007.

[35] H. Bagheri, H. Piri-Moghadam, Recent advances in capillary microextraction, TrAC Trends Anal. Chem. 73 (2015) 64-80.

[36] M.B. Heringa, C. Hogevonder, F. Busser, J.L.M. Hermens, Measurement of the free concentration of octylphenol in biological samples with negligible depletion-solid phase microextraction (ndSPME): Analysis of matrix effects, J. Chromatogr. B Anal. Technol. Biomed. Life Sci. 834 (2006) 35-41.

[37] V.H. Niri, I.Y. Eom, F.R. Kermani, J. Pawliszyn, Sampling free and particle-bound chemicals using solid-phase microextraction and needle trap device simultaneously, J. Sep. Sci. 32 (2009) 1075-1080.

[38] E. Boyac1, Á. Rodríguez-Lafuente, K. Gorynski, F. Mirnaghi, É. a. Souza-Silva, D. Hein, et al., Sample preparation with solid phase microextraction and exhaustive extraction approaches: Comparison for challenging cases, Anal. Chim. Acta. 873 (2014) 14-30.

[39] É.A. Souza-Silva, E. Gionfriddo, J. Pawliszyn, A critical review of the state of art of solid-phase microextraction of complex matrices. Part II: Food Analysis, TrAC Trends Anal. Chem. 71 (2015) 236-248.

[40] B. Bojko, N. Reyes-Garcés, V. Bessonneau, K. Goryński, F. Mousavi, E. a. Souza Silva, et al., Solid-phase microextraction in metabolomics, TrAC - Trends Anal. Chem. 61 (2014) 168-180.

[41] F.S. Mirnaghi, D. Hein, J. Pawliszyn, Thin-film microextraction coupled with mass spectrometry and liquid chromatography-mass spectrometry, Chromatographia. 76 (2013) 1215-1223.

[42] H. Bagheri, H. Piri-Moghadam, M. Naderi, Towards greater mechanical, thermal and chemical stability in solid-phase microextraction, TrAC - Trends Anal. Chem. 34 (2012) 126-138.

[43] R. Jiang, J. Pawliszyn, Thin-film microextraction offers another geometry for solid-phase microextraction, TrAC - Trends Anal. Chem. 39 (2012) 245-253.

[44] E. Beceiro-González, E. Concha-Graña, A. Guimaraes, C. Gonçalves, S. Muniategui-Lorenzo, M.F. Alpendurada, Optimisation and validation of a solid-phase microextraction method for simultaneous determination of different types of pesticides in water by gas chromatography-mass spectrometry., J. Chromatogr. A. 1141 (2007) 165-73.

[45] Angel Rodriguez-Lafuente, H. Piri-Moghadam, H.L. Lord, T. Obal, J. Pawliszyn, An Extensive Study of Automated SPME-GC/MS for determination of pesticides in surface and ground water samples: Sensitive and Green Alternative to Liquid Liquid Extraction, Submitted. (2016).

[46] C. Gonçalves, M.F. Alpendurada, Solid-phase micro-extraction-gas chromatography-(tandem) mass spectrometry as a tool for pesticide residue analysis in water samples at high sensitivity and selectivity with confirmation capabilities, J. Chromatogr. A. 1026 (2004) 239-250.

[47] C. Gonçalves, M.F. Alpendurada, Multiresidue method for the simultaneous determination of four groups of pesticides in ground and drinking waters, using solid-phase microextraction-gas chromatography with electron-capture and thermionic specific detection, J. Chromatogr. A. 968 (2002) 177-190. 
[48] J. Chen, J.B. Pawliszyn, Solid Phase Microextraction Coupled to High-Performance Liquid Chromatography, Anal. Chem. 67 (1995) 2530-2533.

[49] R. Eisert, J. Pawliszyn, Design of automated solid-phase microextraction for trace analysis of organic compounds in aqueous samples, 776 (1997) 293-303.

[50] Y. Gou, C. Tragas, H. Lord, J. Pawliszyn, On-line coupling of in-tube solid phase microextraction (SPME) to HPLC for analysis of carbamates in water samples: Comparison of two commercially available autosamplers, J. Microcolumn Sep. 12 (2000) 125-134.

[51] M. Llompart, M. Lourido, P. Landín, C. García-Jares, R. Cela, Optimization of a derivatizationsolid-phase microextraction method for the analysis of thirty phenolic pollutants in water samples, J. Chromatogr. A. 963 (2002) 137-148.

[52] D.A. Lambropoulou, V.A. Sakkas, T.A. Albanis, Validation of an SPME method, using PDMS, PA, PDMS-DVB, and CW-DVB SPME fiber coatings, for analysis of organophosphorus insecticides in natural waters, Anal. Bioanal. Chem. 374 (2002) 932-941.

[53] A.M. Filho, F.N. dos Santos, P. A D.P. Pereira, Development, validation and application of a method based on DI-SPME and GC-MS for determination of pesticides of different chemical groups in surface and groundwater samples, Microchem. J. 96 (2010) 139-145.

[54] N. Sauret-Szczepanski, P. Mirabel, H. Wortham, Development of an SPME-GC-MS/MS method for the determination of pesticides in rainwater: Laboratory and field experiments, Environ. Pollut. 139 (2006) 133-142.

[55] C. Aguilar, S. Peñalver, E. Pocurull, F. Borrull, R.M. Marcé, Solid-phase microextraction and gas chromatography with mass spectrometric detection for the determination of pesticides in aqueous samples, J. Chromatogr. A. 795 (1998) 105-115.

[56] Y. He, Y. Wang, H.K. Lee, Trace analysis of ten chlorinated benzenes in water by headspace solid-phase microextraction, J. Chromatogr. A. 874 (2000) 149-154.

[57] X. Xu, H. Yang, L. Wang, B. Han, X. Wang, F.S.C. Lee, Analysis of chloroacetanilide herbicides in water samples by solid-phase microextraction coupled with gas chromatography-mass spectrometry, Anal. Chim. Acta. 591 (2007) 87-96.

[58] S.W. Tsai, C.M. Chang, Analysis of aldehydes in water by solid-phase microextraction with onfiber derivatization, J. Chromatogr. A. 1015 (2003) 143-150.

[59] B. Cancho, F. Ventura, M.T. Galceran, Determination of aldehydes in drinking water using pentafluorobenzylhydroxylamine derivatization and solid-phase microextraction, J. Chromatogr. A. 943 (2002) 1-13.

[60] M.L. Bao, F. Pantani, O. Griffini, D. Burrini, D. Santianni, K. Barbieri, Determination of carbonyl compounds in water by derivatization-solid-phase microextraction and gas chromatographic analysis., J. Chromatogr. A. 809 (1998) 75-87.

[61] C. V. Antoniou, E.E. Koukouraki, E. Diamadopoulos, Determination of chlorinated volatile organic compounds in water and municipal wastewater using headspace-solid phase microextraction-gas chromatography, J. Chromatogr. A. 1132 (2006) 310-314.

[62] M. Llompart, K. Li, M. Fingas, Headspace solid-phase microextraction for the determination of volatile and semi-volatile pollutants in water and air., J. Chromatogr. A. 824 (1998) 53-61.

[63] A.J. King, J.W. Readman, J.L. Zhou, Determination of polycyclic aromatic hydrocarbons in water by solid-phase microextraction-gas chromatography-mass spectrometry, Anal. Chim. Acta. 523 (2004) 259-267. 
[64] R.A. Doong, S.M. Chang, Y.C. Sun, Solid-phase microextraction for determining the distribution of sixteen US Environmental Protection Agency polycyclic aromatic hydrocarbons in water samples., J. Chromatogr. A. 879 (2000) 177-188.

[65] V. Fernández-González, E. Concha-Graña, S. Muniategui-Lorenzo, P. López-Mahía, D. PradaRodríguez, Solid-phase microextraction-gas chromatographic-tandem mass spectrometric analysis of polycyclic aromatic hydrocarbons. Towards the European Union water directive 2006/0129 EC, J. Chromatogr. A. 1176 (2007) 48-56.

[66] P. Popp, C. Bauer, M. Möder, A. Paschke, Determination of polycyclic aromatic hydrocarbons in waste water by off-line coupling of solid-phase microextraction with column liquid chromatography., J. Chromatogr. A. 897 (2000) 153-159.

[67] M.R. Negrão, M.F. Alpendurada, Solvent-free method for the determination of polynuclear aromatic hydrocarbons in waste water by solid-phase microextraction-high-performance liquid chromatography with photodiode-array detection, J. Chromatogr. A. 823 (1998) 211-218.

[68] M. Polo, M. Llompart, C. Garcia-Jares, G. Gomez-Noya, M.H. Bollain, R. Cela, Development of a solid-phase microextraction method for the analysis of phenolic flame retardants in water samples, J. Chromatogr. A. 1124 (2006) 11-21.

[69] N.G. Simões, V.V. Cardoso, E. Ferreira, M.J. Benoliel, C.M.M. Almeida, Experimental and statistical validation of SPME-GC-MS analysis of phenol and chlorophenols in raw and treated water, Chemosphere. 68 (2007) 501-510.

[70] S. Zhou, J. Huang, X. Gao, L. Zhao, SPME-GC-MSD for Determination of Nine Phenyl Compounds in Snow Water in Beijing China, Chromatographia. 62 (2005) 109-111.

[71] W.-Y. Chang, Y.-H. Sung, S.-D. Huang, Analysis of carcinogenic aromatic amines in water samples by solid-phase microextraction coupled with high-performance liquid chromatography, Anal. Chim. Acta. 495 (2003) 109-122.

[72] S. Frías, M.A. Rodríguez, J.E. Conde, J.P. Pérez-Trujillo, Optimisation of a solid-phase microextraction procedure for the determination of triazines in water with gas chromatographymass spectrometry detection, J. Chromatogr. A. 1007 (2003) 127-135.

[73] Y. Yang, D.J. Miller, S.B. Hawthorne, Solid-phase microextraction of polychlorinated biphenyls., J. Chromatogr. A. 800 (1998) 257-266.

[74] A. Derouiche, M.R. Driss, J.-P. Morizur, M.-H. Taphanel, Simultaneous analysis of polychlorinated biphenyls and organochlorine pesticides in water by headspace solid-phase microextraction with gas chromatography-tandem mass spectrometry., J. Chromatogr. A. 1138 (2007) 231-243.

[75] J.L. Raposo Júnior, N. Ré-Poppi, Determination of organochlorine pesticides in ground water samples using solid-phase microextraction by gas chromatography-electron capture detection., Talanta. 72 (2007) 1833-1841.

[76] J.P. Pérez-Trujillo, S. Frías, J.E. Conde, M.A. Rodríguez-Delgado, Comparison of different coatings in solid-phase microextraction for the determination of organochlorine pesticides in ground water, J. Chromatogr. A. 963 (2002) 95-105.

[77] D.A. Lambropoulou, T.A. Albanis, Optimization of headspace solid-phase microextraction conditions for the determination of organophosphorus insecticides in natural waters, J. Chromatogr. A. 922 (2001) 243-255. 
[78] J. Beltran, F.J. Lopez, O. Cepria, F. Hernandez, Solid-phase microextraction for quantitative analysis of organophosphorus pesticides in environmental water samples, 808 (1998) 257-263.

[79] J. Carpinteiro, J.B. Quintana, E. Martínez, I. Rodríguez, a. M. Carro, R. a. Lorenzo, et al., Application of strategic sample composition to the screening of anti-inflammatory drugs in water samples using solid-phase microextraction, Anal. Chim. Acta. 524 (2004) 63-71.

[80] L. Araujo, J. Wild, N. Villa, N. Camargo, D. Cubillan, A. Prieto, Determination of antiinflammatory drugs in water samples, by in situ derivatization, solid phase microextraction and gas chromatography-mass spectrometry, Talanta. 75 (2008) 111-115.

[81] G. Zhuang, Y. Lin, M. Elvert, V.B. Heuer, K. Hinrichs, Gas chromatographic analysis of methanol and ethanol in marine sediment pore waters : Validation and implementation of three pretreatment techniques, Mar. Chem. 160 (2014) 82-90.

[82] A. Martinez, C.O. Sullivan, D. Reible, K.C. Hornbuckle, Sediment pore water distribution coef fi cients of PCB congeners in enriched black carbon sediment, Environ. Pollut. 182 (2013) 357-363.

[83] K. Luks-Betlej, P. Popp, B. Janoszka, H. Paschke, Solid-phase microextraction of phthalates from water, J. Chromatogr. A. 938 (2001) 93-101.

[84] X.-L. Cao, Determination of phthalates and adipate in bottled water by headspace solid-phase microextraction and gas chromatography/mass spectrometry., J. Chromatogr. A. 1178 (2008) 231238.

[85] A. Peñalver, E. Pocurull, F. Borrull, R.M. Marcé, Comparison of different fibers for the solidphase microextraction of phthalate esters from water, J. Chromatogr. A. 922 (2001) 377-384.

[86] Y.H. Sung, T.Y. Li, S. Da Huang, Analysis of earthy and musty odors in water samples by solidphase microextraction coupled with gas chromatography/ion trap mass spectrometry, Talanta. 65 (2005) 518-524.

[87] K. Saito, K. Okamura, H. Kataoka, Determination of musty odorants, 2-methylisoborneol and geosmin, in environmental water by headspace solid-phase microextraction and gas chromatography-mass spectrometry, J. Chromatogr. A. 1186 (2008) 434-437.

[88] B. Cancho, F. Ventura, M.T. Galceran, Solid-phase microextraction for the determination of iodinated trihalomethanes in drinking water, J. Chromatogr. A. 841 (1999) 197-206.

[89] M. Bahri, M.R. Driss, Development of solid-phase microextraction for the determination of trihalomethanes in drinking water from Bizerte, Tunisia, Desalination. 250 (2010) 414-417.

[90] D.H. Cho, S.H. Kong, S.G. Oh, Analysis of trihalomethanes in drinking water using headspaceSPME technique with gas chromatography, Water Res. 37 (2003) 402-408.

[91] M. Abalos, J.M. Bayon, J. Pawliszyn, Development of a headspace solid-phase microextraction procedure for the determination of free volatile fatty acids in waste waters., J. Chromatogr. A. 873 (2000) 107-115.

[92] S.P. Yo, Analysis of volatile fatty acids in wastewater collected from a pig farm by a solid phase microextraction method, Chemosphere. 38 (1999) 823-834.

[93] M.I. Helaleh, S. Fujii, T. Korenaga, Column silylation method for determining endocrine disruptors from environmental water samples by solid phase micro-extraction., Talanta. 54 (2001) 1039-1047. 
[94] K. Mitani, H. Kataoka, Determination of fluoroquinolones in environmental waters by in-tube solid-phase microextraction coupled with liquid chromatography-tandem mass spectrometry, Anal. Chim. Acta. 562 (2006) 16-22.

[95] D.A. Lambropoulou, I.K. Konstantinou, T.A. Albanis, Determination of fungicides in natural waters using solid-phase microextraction and gas chromatography coupled with electron-capture and mass spectrometric detection., J. Chromatogr. A. 893 (2000) 143-156.

[96] L. Segovia-Martínez, a. Bouzas-Blanco, P. Campíns-Falcó, a. Seco-Torrecillas, Improving detection limits for organotin compounds in several matrix water samples by derivatizationheadspace-solid-phase microextraction and GC-MS, Talanta. 80 (2010) 1888-1893.

[97] C.-C. Chou, M.-R. Lee, Determination of organotin compounds in-water by headspace solid phase microextraction with gas chromatography-mass spectrometry., J. Chromatogr. A. 1064 (2005) 18.

[98] P. Canosa, I. Rodríguez, E. Rubí, M.H. Bollaín, R. Cela, Optimisation of a solid-phase microextraction method for the determination of parabens in water samples at the low ng per litre level, J. Chromatogr. A. 1124 (2006) 3-10.

[99] M.N. Sarrion, F.J. Santos, M.T. Galceran, Solid-phase microextraction coupled with gas chromatography-ion trap mass spectrometry for the analysis of haloacetic acids in water, J. Chromatogr. A. 859 (1999) 159-171.

[100] A. Penalver, E. Pocurull, F. Borrull, R.M. Marce, M ethod based on solid-phase microextraction high-performance liquid chromatography with UV and electrochemical detection to determine estrogenic compounds in water samples, J. Chromatogr. A. 964 (2002) 153-160.

[101] H.-H. Lin, Y.-H. Sung, S.-D. Huang, Solid-phase microextraction coupled with high-performance liquid chromatography for the determination of phenylurea herbicides in aqueous samples., J. Chromatogr. A. 1012 (2003) 57-66.

[102] International Organization for Standardization (2013) ISO 27108:2013: Water quality., (n.d.).

[103] F. Michel, F. Werres, Y. Chen, B. Shirey, Determination of volatile organic compounds in water by SPME and GC/MS: Validation of new ISO Standard 17943, Supelco/Sigma-Aldrich.

[104] American society for testing and materials (2000) ASTM D 6520, 2000.

[105] American society for testing and materials (2003) ASTM D 6889, 2003.

[106] T. Gorecki, R. Mindrup, J. Pawliszyn, Pesticides by Sol id-p hase Microext raction. Results of a Round Robin Test*, Analyst. 121 (1996) 1381-1386.

[107] T. Nilsson, R. Ferrari, S. Facchetti, Inter-laboratory studies for the validation of solid-phase microextraction for the quantitative analysis of volatile organic compounds in aqueous samples, Anal. Chim. Acta. 356 (1997) 113-123.

[108] R. Ferrari, T. Nilsson, R. Arena, P. Arlati, G. Bartolucci, R. Basla, et al., Inter-laboratory validation of solid-phase microextraction for the determination of triazine herbicides and their degradation products at ng/1 level in water samples, J. Chromatogr. A. 795 (1998) 371-376.

[109] S. Guillot, M.T. Kelly, H. Fenet, M. Larroque, Evaluation of solid-phase microextraction as an alternative to the official method for the analysis of organic micro-pollutants in drinking water, J. Chromatogr. A. 1101 (2006) 46-52. 
[110] F. Bonadio, P. Margot, O. Delémont, P. Esseiva, Headspace solid-phase microextraction (HSSPME) and liquid-liquid extraction (LLE): comparison of the performance in classification of ecstasy tablets. Part 2., Forensic Sci. Int. 182 (2008) 52-6.

[111] F.R. Kermani, A.-M. Tugulea, J. Hnatiw, V.H. Niri, J. Pawliszyn, Application of automated solidphase microextraction to determine haloacetonitriles, haloketones, and chloropicrin in Canadian drinking water, Water Qual. Res. J. Canada. 48 (2013) 85.

[112] Farhad, Riazi Kermani, Optimization of Solid Phase Microextraction for Determination of Disinfection By-products in Water, PhD thesis, University of Waterloo, Waterloo, 2012, Chapter 3., (2012).

[113] A. Gałuszka, Z.M. Migaszewski, P. Konieczka, J. Namieśnik, Analytical Eco-Scale for assessing the greenness of analytical procedures, TrAC - Trends Anal. Chem. 37 (2012) 61-72.

[114] M. Sakamoto, T. Tsutsumi, Applicability of headspace solid-phase microextraction to the determination of multi-class pesticides in waters, J. Chromatogr. A. 1028 (2004) 63-74.

[115] V. Jezová, J. Skládal, A. Eisner, P. Bajerová, K. Ventura, Determination of nitrate esters in water samples Comparison of efficiency of solid-phase extraction and solid-phase microextraction., J. Chromatogr. A. 1174 (2007) 13-9.

[116] D.A. Lambropoulou, T. Sakellarides, T. Albanis, Determination of organophosphorus insecticides in natural waters using SPE-disks and SPME followed by GC/FTD and GC/MS., Fresenius. J. Anal. Chem. 368 (2000) 616-23.

[117] V.K. Balakrishnan, K. a. Terry, J. Toito, Determination of sulfonamide antibiotics in wastewater: A comparison of solid phase microextraction and solid phase extraction methods, J. Chromatogr. A. 1131 (2006) 1-10.

[118] P. Castells, F.J. Santos, M.T. Galceran, Solid-phase extraction versus solid-phase microextraction for the determination of chlorinated paraffins in water using gas chromatography- negative chemical ionisation mass spectrometry, J. Chromatogr. A. 1025 (2004) 157-162.

[119] M.A. Dalvie, E. Sinanovic, L. London, E. Cairncross, A. Solomon, H. Adam, Cost analysis of ELISA, solid-phase extraction, and solid-phase microextraction for the monitoring of pesticides in water., Environ. Res. 98 (2005) 143-50.

[120] B. MacGillivray, J. Pawliszyn, P. Fowlie, C. Sagara, Headspace Solid-Phase Microextraction versus Purge and Trap for the Determination of Substituted Benzene Compounds in Water, J. Chromatogr. Sci. 32 (1994) 317-322.

[121] A. Lara-Gonzalo, J.E. Sánchez-Uría, E. Segovia-García, A. Sanz-Medel, Critical comparison of automated purge and trap and solid-phase microextraction for routine determination of volatile organic compounds in drinking waters by GC-MS, Talanta. 74 (2008) 1455-1462.

[122] M. Vogt, S. Turner, N. Yassaa, M. Steinke, J. Williams, P. Liss, Laboratory inter-comparison of dissolved dimethyl sulphide (DMS) measurements using purge-and-trap and solid-phase microextraction techniques during a mesocosm experiment, Mar. Chem. 108 (2008) 32-39.

[123] B. MacGillivray, J. Pawliszyn, P. Fowlie, C. Sagara, Headspace Solid-Phase Microextraction versus Purge and Trap for the Determination of Substituted Benzene Compounds in Water, J. Chromatogr. Sci. 32 (1994) 317-322.

[124] M.D.F. Alpendurada, Solid-phase microextraction : a promising technique for sample preparation in environmental analysis, J Chromatogr.A. 889 (2000) 3-14.

[125] I. Bruheim, X. Liu, J. Pawliszyn, Thin-Film Microextraction, 75 (2003) 1002-1010. 
[126] F. Riazi Kermani, J. Pawliszyn, Sorbent coated glass wool fabric as a thin film microextraction device, Anal. Chem. 84 (2012) 8990-8995.

[127] N. Strittmatter, R.-A. Düring, Z. Takáts, Analysis of wastewater samples by direct combination of thin-film microextraction and desorption electrospray ionization mass spectrometry, Analyst. 137 (2012) 4037.

[128] R. Kumar, Gaurav, Heena, A.K. Malik, A. Kabir, K.G. Furton, Efficient analysis of selected estrogens using fabric phase sorptive extraction and high performance liquid chromatographyfluorescence detection., J. Chromatogr. A. 1359 (2014) 16-25.

[129] S. Montesdeoca-Esponda, Z. Sosa-Ferrera, A. Kabir, K.G. Furton, J.J. Santana-Rodríguez, Fabric phase sorptive extraction followed by UHPLC-MS/MS for the analysis of benzotriazole UV stabilizers in sewage samples, Anal. Bioanal. Chem. (2015) 8137-8150.

[130] I. Racamonde, R. Rodil, J.B. Quintana, B.J. Sieira, A. Kabir, K.G. Furton, et al., Fabric phase sorptive extraction: A new sorptive microextraction technique for the determination of nonsteroidal anti-inflammatory drugs from environmental water samples, Anal. Chim. Acta. 865 (2015) 22-30.

[131] R. Kumar, Gaurav, A. Kabir, K.G. Furton, A.K. Malik, Development of a fabric phase sorptive extraction with high-performance liquid chromatography and ultraviolet detection method for the analysis of alkyl phenols in environmental samples, J. Sep. Sci. 38 (2015) 3228-3238.

[132] S.S. Lakade, F. Borrull, K.G. Furton, A. Kabir, N. Fontanals, R.M. Marcé, Comparative study of different fabric phase sorptive extraction sorbents to determine emerging contaminants from environmental water using liquid chromatography-tandem mass spectrometry, Talanta. 144 (2015) 1342-1351.

[133] J.J. Grandy, E. Boyaci, J. Pawliszyn, Development of a Carbon Mesh Supported Thin Film Microextraction Membrane As a Means to Lower the Detection Limits of Benchtop and Portable GC/MS Instrumentation, Anal. Chem. 88 (2016) 1760-1767.

[134] E. Cudjoe, D. Vuckovic, D. Hein, J. Pawliszyn, Investigation of the Effect of the Extraction Phase Geometry on the Performance of Automated Solid-Phase Microextraction, 81 (2009) 4226-4232.

[135] P. Kueseng, J. Pawliszyn, Carboxylated multiwalled carbon nanotubes / polydimethylsiloxane , a new coating for 96-blade solid-phase microextraction for determination of phenolic compounds in water, J. Chromatogr. A. 1317 (2013) 199-202.

[136] E. Boyac, C. Sparham, J. Pawliszyn, Thin-film microextraction coupled to LC-ESI-MS / MS for determination of quaternary ammonium compounds in water samples, Anal. Bioanal. Che., 406 (2014) 409-420.

[137] O.P. Togunde, E. Cudjoe, K.D. Oakes, F.S. Mirnaghi, M.R. Servos, J. Pawliszyn, Determination of selected pharmaceutical residues in wastewater using an automated open bed solid phase microextraction system, J. Chromatogr. A. 1262 (2012) 34-42.

[138] F.S. Mirnaghi, K. Gory, A. Rodriguez-lafuente, E. Boyac1, B. Bojko, J. Pawliszyn, Microextraction versus exhaustive extraction approaches for simultaneous analysis of compounds in wide range of polarity, J. Chromatogr. A. 1316 (2013) 37-43.

[139] J. Pawliszyn, Why move analysis from laboratory to on-site?, TrAC Trends Anal. Chem. 25 (2006) 633-634.

[140] G. Ouyang, J. Cai, X. Zhang, H. Li, J. Pawliszyn, Standard-free kinetic calibration for rapid onsite analysis by solid-phase microextraction., J. Sep. Sci. 31 (2008) 1167-72. 
[141] Z. Qin, L. Bragg, G. Ouyang, V.H. Niri, J. Pawliszyn, Solid-phase microextraction under controlled agitation conditions for rapid on-site sampling of organic pollutants in water., J. Chromatogr. A. 1216 (2009) 6979-85.

[142] Y. Chen, J. Pawliszyn, Time-weighted average passive sampling with a solid-phase microextraction device., Anal. Chem. 75 (2003) 2004-10.

[143] G. Ouyang, W. Zhao, L. Bragg, Z. Qin, M. Alaee, J. Pawliszyn, Time-weighted average water sampling in Lake Ontario with solid-phase microextraction passive samplers., Environ. Sci. Technol. 41 (2007) 4026-31.

[144] L. Bragg, Z. Qin, M. Alaee, J. Pawliszyn, Field sampling with a polydimethylsiloxane thin-film., J. Chromatogr. Sci. 44 (2006) 317-23.

[145] W. Zhao, G. Ouyang, M. Alaee, J. Pawliszyn, On-rod standardization technique for time-weighted average water sampling with a polydimethylsiloxane rod., J. Chromatogr. A. 1124 (2006) 112-20.

[146] G. Ouyang, S. Cui, Z. Qin, J. Pawliszyn, One-calibrant kinetic calibration for on-site water sampling with solid-phase microextraction, Anal. Chem. 81 (2009) 5629-5636.

[147] G. Ouyang, W. Zhao, M. Alaee, J. Pawliszyn, Time-weighted average water sampling with a diffusion-based solid-phase microextraction device., J. Chromatogr. A. 1138 (2007) 42-6.

[148] S. Risticevic, V.H. Niri, D. Vuckovic, J. Pawliszyn, Recent developments in solid-phase microextraction., Anal. Bioanal. Chem. 393 (2009) 781-95.

[149] B. Vrana, I.J. Allan, R. Greenwood, G. a. Mills, E. Dominiak, K. Svensson, et al., Passive sampling techniques for monitoring pollutants in water, TrAC Trends Anal. Chem. 24 (2005) 845868.

[150] S. Seethapathy, T. Górecki, X. Li, Passive sampling in environmental analysis., J. Chromatogr. A. 1184 (2008) 234-53.

[151] T. Górecki, J. Namienik, Passive sampling, TrAC - Trends Anal. Chem. 21 (2002) 276-291.

[152] G. Ouyang, K.D. Oakes, L. Bragg, S. Wang, H. Liu, S. Cui, et al., Sampling-rate calibration for rapid and nonlethal monitoring of organic contaminants in fish muscle by solid-phase microextraction., Environ. Sci. Technol. 45 (2011) 7792-8.

[153] G. Ouyang, J. Pawliszyn, Configurations and calibration methods for passive sampling techniques., J. Chromatogr. A. 1168 (2007) 226-35; discussion 225.

[154] S.N. Zhou, X. Zhang, G. Ouyang, A. Es-haghi, J. Pawliszyn, On-Fiber Standardization Technique for Solid-Coated Solid-Phase Microextraction, Anal. Chem. 79 (2007) 1221-1230.

[155] Y. Chen, J. Pawliszyn, Kinetics and the on-site application of standards in a solid-phase microextraction fiber., Anal. Chem. 76 (2004) 5807-15.

[156] Y. Chen, J. a. Koziel, J. Pawliszyn, Calibration for On-Site Analysis of Hydrocarbons in Aqueous and Gaseous Samples Using Solid-Phase Microextraction, Anal. Chem. 75 (2003) 6485-6493.

[157] S.N. Zhou, W. Zhao, J. Pawliszyn, Kinetic calibration using dominant pre-equilibrium desorption for on-site and in vivo sampling by solid-phase microextraction, Anal. Chem. 80 (2008) 481-490.

[158] D. A. Alvarez, P.E. Stackelberg, J.D. Petty, J.N. Huckins, E.T. Furlong, S.D. Zaugg, et al., Comparison of a novel passive sampler to standard water-column sampling for organic contaminants associated with wastewater effluents entering a New Jersey stream., Chemosphere. 61 (2005) 610-22. 
[159] J. Cristale, A. Katsoyiannis, C. Chen, K.C. Jones, S. Lacorte, Assessment of flame retardants in river water using a ceramic dosimeter passive sampler, Environ. Pollut. 172 (2013) 163-169.

[160] Y. Chen, J. Pawliszyn, Time-weighted average passive sampling with a Solid-Phase Microextraction device, Anal. Chem. 75 (2003) 2004-2010.

[161] P. A. Martos, J. Pawliszyn, Time-weighted average sampling with solid-phase microextraction device: implications for enhanced personal exposure monitoring to airborne pollutants., Anal. Chem. 71 (1999) 1513-20.

[162] Fardin , Ahmadi , New Strategies for Analysis of Particulate Loaded Water , PhD thesis , University of Waterloo, 2016, Chapter 3, (2016).

[163] B. Shurmer, J. Pawliszyn, Determination of distribution constants between a liquid polymeric coating and water by a solid-phase microextraction technique with a flow-through standard water system, Anal. Chem. 72 (2000) 3660-4.

[164] G. Ouyang, Y. Chen, J. Pawliszyn, Flow-through system for the generation of standard aqueous solution of polycyclic aromatic hydrocarbons., J. Chromatogr. A. 1105 (2006) 176-9.

[165] H.L. Lord, J. Pawliszyn, Method optimization for the analysis of amphetamines in urine by solidphase microextraction., Anal. Chem. 69 (1997) 3899-906.

[166] Fardin , Ahmadi , New Strategies for Analysis of Particulate Loaded Water , PhD thesis , University of Waterloo, 2016, Chapter 4, (2016).

[167] O.P. Togunde, K.D. Oakes, M.R. Servos, J. Pawliszyn, Optimization of solid phase microextraction for non-lethal in vivo determination of selected pharmaceuticals in fish muscle using liquid chromatography - mass spectrometry, J. Chromatogr. A. 1261 (2012) 99-106. 


\section{Figures caption}

Fig. 1) a) TFME sampler, Teflon holder and extraction set-up; b) 96-blade configuration c)

Manual kit for high-throughput sampling. Reprinted with permission from [126] Copyright [2012] American Chemical Society; reprinted from [41] and [136] with permission of Springer 2013,2014).

Fig. 2. a) SPME sampler for on-site sampling, b) Scheme of thin film and fiber used for on-site sampling of river water. (Reprinted with permission from [141] @ Elsevier [2009]; reprinted from [148] with permission of Springer 2009).

Fig. 3. On-site sampling by thin-film passive samplers: (a) thin-film HLB retracted device, (b) PDMS membrane (c) thin film blade (d) copper bag, (e) sampler plastic cage (Reprinted from [148] with permission of Springer 2009).

Fig. 4. Schematic diagram of new flow-through system for generation of standard aqueous solution of UV blockers and biocides [166] ; Octyl methoxycinnamate (OMC), benzophenone-4 (Ben-4), 2phenylbenzimidazole-5-sulphonic acid (PBSA), octocrylene (OCR)

Fig. 1. 
a)

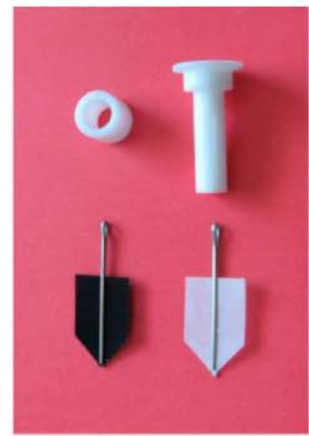

b)

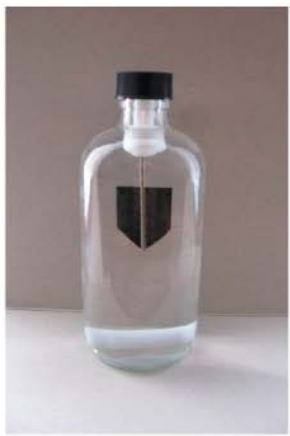

c)

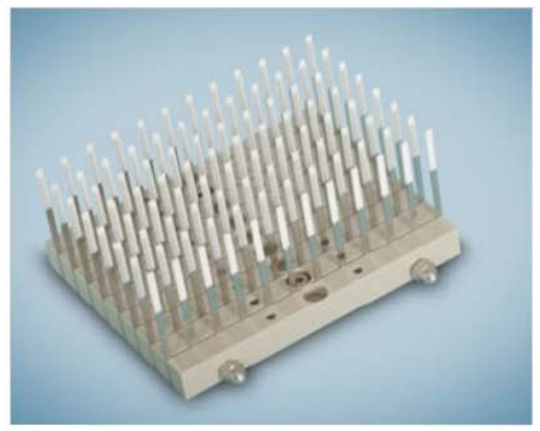


Fig. 2.

a)

b)

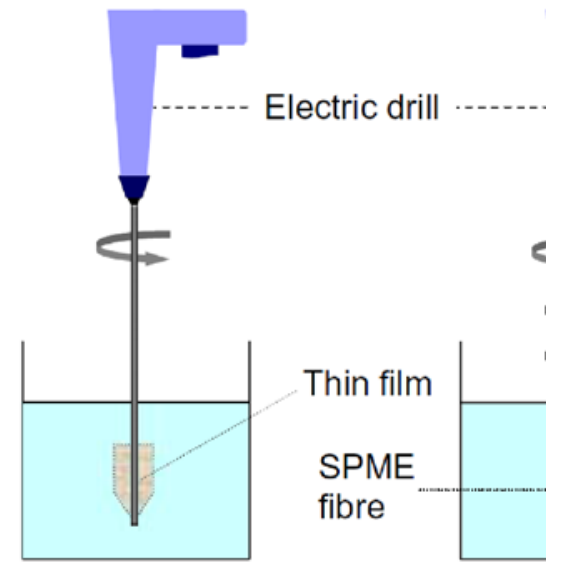


Fig. 3.

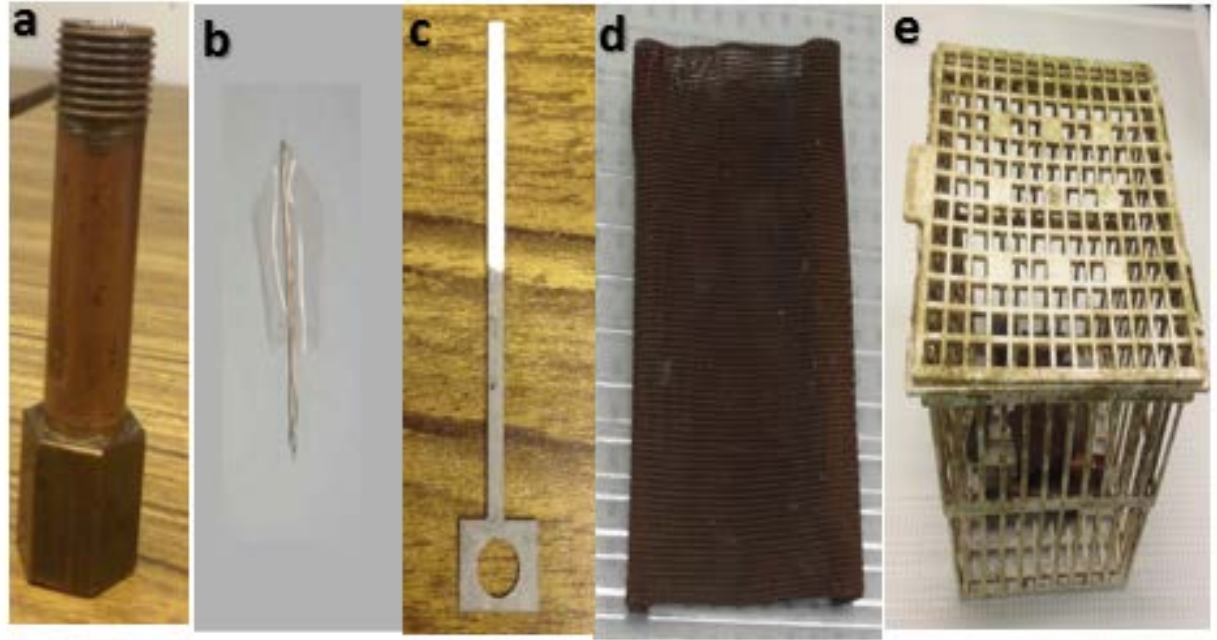


Fig. 4.

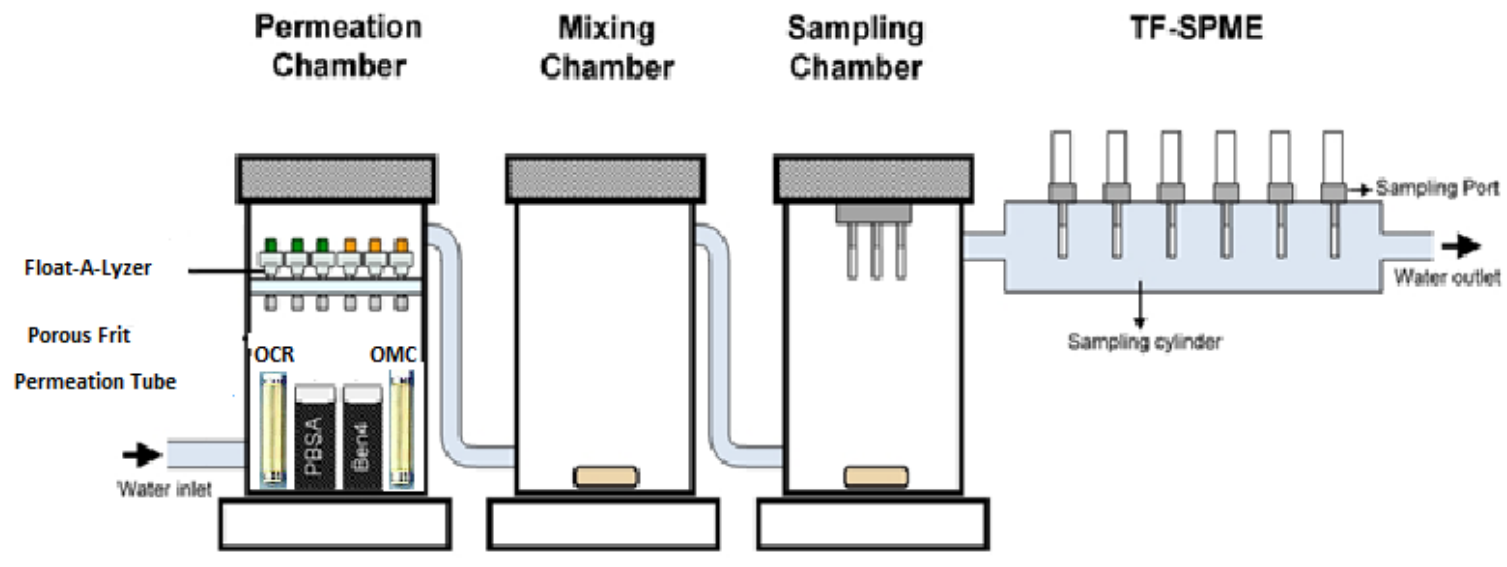


Table 1- Summary of application of SPME for determination of organic pollutants in water samples

\begin{tabular}{|c|c|c|c|c|}
\hline Compounds & Matrix & SPME fiber & Instrument & Ref. \\
\hline $\begin{array}{lll}\text { Pesticides }^{*} & \text { [Organochlorine } & \text { (OCPs), }\end{array}$ & Ground, drinking, & PDMS/DVB & GC/MS & {$[44-47,51-$} \\
\hline $\begin{array}{l}\text { Organophosphorous (OPPs), triazines, carbamates, } \\
\text { polychlorinated biphenyls (PCBs) and phenolic }\end{array}$ & $\begin{array}{l}\text { lake, river and rain } \\
\text { water }\end{array}$ & & & 55] \\
\hline \multicolumn{5}{|l|}{ compounds groups] } \\
\hline Chlorinated benzenes & Natural water & PDMS & GC/MS & {$[56]$} \\
\hline Chloroacetanilide herbicides & River water & PDMS & GC/MS & [57] \\
\hline Aldehydes & Drinking and well & PDMS, PDMS/DVB & GC/MS, GC-ECD & [58-60] \\
\hline Semi volatile organic compounds (VOCs), VOCs & Drinking and waste & PDMS, CAR/PDMS & GC-ECD & {$[61,62]$} \\
\hline \multirow[t]{6}{*}{ and Chlorinated VOCs } & water & & & \\
\hline & Sediment pore water, & CAR/PDMS, & GC/MS & {$[34,63-65]$} \\
\hline & River, sea and ground & PDMS/DVB & & \\
\hline & water & & & \\
\hline & Ground and waste & PDMS & LC-Flu, & {$[66,67]$} \\
\hline & water & & LC-PDA & \\
\hline Phenolic compounds & River and waste water & PDMS, PA, CAR/PDMS & GC/MS & {$[51,68,69]$} \\
\hline Phenyl Compounds & Snow water & PDMS & GC/MS & {$[70]$} \\
\hline Aromatic amines & Natural water & PDMS & HPLC & {$[71]$} \\
\hline
\end{tabular}


Triazines

PCBs

OCPs

OPPs

Anti-inflammatory drugs

PAHs, Methanol and ethanol, PCBs

Phthalate and adipate

Earthy and musty odors

Trihalomethanes (THMs)

Volatile fatty acid
Ground water

PDMS/DVB

GC-MS

[72]

Ocean, wetland and

PDMS, PDMS/DVB

GC-ECD, GC/MS

$[73,74]$

leachate water, river

Ground water, river

DVB/CAR/PDMS

GC-ECD, GC/MS

[74-76]

River and ground PDMS, PA

GC-FPD, GC-FTD,

$[77,78]$

water

GC-NPD GC-MS

River and waste water

PA, PDMS

GC/MS

$[79,80]$

Sediment pore water

PDMS, CAR/PDMS

GC/MS

$[34,81,82]$

Drinking and river

CAR/DVB, PDMS/DVB

GC/MS

[83-85]

water

Lake water

PDMS/DVB, DVB/CAR/PDMS

GC-MS

[86,87]

Drinking water

PDMS,

CAR/PDMS, GC-ECD

[88-90]

CWX/DVB

Waste water

PDMS/CAR

GC-FID, GC/MS

$[91,92]$ 
Endocrine disruptors

Fluoroquinolones

Fungicides

Organotonin compounds

Parabens

Haloacetic acids (HAAs)

Estrogenic compounds

Phenylurea herbicides
River, sea and PA

underground water

River and waste water Carboxen (In-tube SPME)

Ground, sea, river and PDMS

GC-ECD, GC-MS

[95]

lake water

Sea and waste water

PDMS

GC/MS

[96,97]

Sewage water

PA

GC/MS

[98]

Drinking water

PDMS

GC/MS

[99]

River and waste water

PA

LC-UV-ED

[100]

Lake water

LC-UV

\footnotetext{
${ }^{*}$ Simoultanous determination of several groups
} 
Table 2- Official methods/standards of SPME in water analysis

\begin{tabular}{lllc}
\hline No. & Official method/standard & Description & Ref. \\
\hline 1 & US EPA Method 8272 & Determination of PAHs in sediment pore water & {$[34]$} \\
2 & ISO 27108 & Determination of selected plant treatment & {$[102]$} \\
& & agents and biocide products & \\
3 & ISO 17943 & Determination of VOCs by HS-SPME & {$[103]$} \\
4 & ASTM D 6520 & HS analysis of semi-VOCs and VOCs & {$[104]$} \\
5 & ASTM D 6889 & Fast screening of VOCs & {$[105]$} \\
\hline
\end{tabular}


Table 3- Comparison of SPME fiber with EPA-approved methods [45,111,114,115,120,124]

\begin{tabular}{|c|c|c|c|c|}
\hline & LLE & SPE & P\&T & SPME fiber \\
\hline $\begin{array}{l}\text { Extraction- } \\
\text { determination }\end{array}$ & $\begin{array}{l}\text { - Addition of organic solvent } \\
\text { to the original bottle or } \\
\text { separatory funnel } \\
\text { - Agitation } \\
\text { - Separation of the two } \\
\text { phases } \\
\text {-Evaporation/ reconstitution/ } \\
\text { concentration } \\
\text { - Injection to the instruments }\end{array}$ & $\begin{array}{l}\text { - Conditioning of cartridge } \\
\text { with solvents } \\
\text { - Loading of sample } \\
\text { - Washing step } \\
\text { - Desorption } \\
\text { - Evaporation/ } \\
\text { reconstitution/concentration } \\
\text { - Injection to the } \\
\text { instruments }\end{array}$ & $\begin{array}{l}\text { - Passing of } \\
\text { purging gas (He or } \\
\mathrm{N}_{2} \text { ) and trapping } \\
\text { the compounds } \\
\text { - Desorption and } \\
\text { introduction to GC }\end{array}$ & $\begin{array}{l}\text { - Direct/HS extraction } \\
\text { - Desorption in } \\
\text { instruments }\end{array}$ \\
\hline Sample volume & Up to $1000 \mathrm{~mL}$ & $100-500 \mathrm{~mL}$ & $5-25 \mathrm{~mL}$ & $2-10 \mathrm{~mL}$ \\
\hline Solvent volume & Up to $100 \mathrm{~mL}$ & $5-10 \mathrm{~mL}$ & $<50 \mu \mathrm{L}$ & $<50 \mu \mathrm{L}$ \\
\hline Extraction time & $60 \mathrm{~min}$ & $30-60 \mathrm{~min}$ & $10-30 \mathrm{~min}$ & $10-60 \mathrm{~min}$ \\
\hline Greenness & Poor & Fair & Excellent & Excellent \\
\hline LOD & $0.5-5 \mathrm{ng} \mathrm{mL}^{-1}$ & $0.005-0.05 \mathrm{ng} \mathrm{mL}^{-1}$ & $0.05-0.5 \mathrm{ng} \mathrm{mL}^{-1}$ & $0.05-0.5 \mathrm{ng} \mathrm{mL}^{-1}$ \\
\hline
\end{tabular}

